\title{
Observation and Modeling of North Atlantic Deep Water Formation and its Variability: Introduction
}

\author{
Thomas F. Stocker ${ }^{1}$ and Wallace S. Broecker \\ Lamont-Doherty Earth Observatory, Columbia University, Palisades
}

This Special Section is the result of a 2-day miniconference held at Lamont-Doherty Earth Observatory in November 1991. The purpose of that meeting was to review the current knowledge of North Atlantic Deep Water (NADW) formation and to discuss the role of the global circulation it sets up in the climate system [Broecker, 1991]. The present collection of papers, however, goes beyond the original scope of the meeting and is more up-to-date than a mere proceedings volume.

To obtain data on the formation and circulation of the deep water by classical oceanographic observation methods is a difficult task. It is therefore necessary to try to fill the various gaps in knowledge by combining information from observations with what we can learn from an entire hierarchy of numerical models. This philosophy was behind the 1991 miniconference [Stocker and Brocker, 1992] and is also reflected in this special section. Although the degree of interaction must continue to increase, such meetings are valuable starting points for a closer communication between modelers and those collecting and producing the data which is so crucial for model validation. It is the purpose of this special section to make a contribution towards this aim.

The range of papers illustrates the key importance of NADW formation in the climate system. The observational studies address the question of different pathways of deep currents in the North Atlantic basin. The major contributor to NADW is the outflow of the Greenland basin. It is remarkably constant, as long-term current measurements indicate, but locally, large fluctuations can be observed in complex terrain. Three-dimensional simulations elucidate the role of topography in determining the general circulation and allow the estimation of adjustment timescales when sources are varying.

While the history of the end product NADW is difficult to trace even today, the influence of this circulation on climate can be reconstructed for the past several tens of thousands of years. There is evidence that millennial scale variability is linked to or caused by oscillations of NADW formation.

Variability of the deep water circulation is a central topic of modeling studies in this special section. Lengthscales and timescales of such fluctuations range from regional to global and from decades to millennia, respectively. These processes are therefore important not only to understand the large fluctuations during the past but also to obtain a feel for the natural variability of the climate system. Models indicate that the North Atlantic / Labrador Sea region is a central location of the generation of internal variability on interdecadal timescales. One may therefore speculate that interdecadal fluctuations evident in proxy records for surface air temperature also have their origin in the ocean [Stocker, 1994].

\section{References}

Broecker, W. S., The great ocean conveyor, Oceanography, 4, 79-89, 1991.

Stocker, T. F., The variable ocean, Nature, 36\%, 221-222, 1994.

Stocker, T. F., and W. S. Broecker, NADW formation as a branch of the hydrological cycle, Eos Trans. AGU, 73 (18), 202-203, 1992.

W. S. Broecker, Lamont-Doherty Earth Observatory, Columbia University, Palisades, NY, 10964.

T. F. Stocker, Physics Institute, University of Bern, Sidlerstr. 5, 3012 Bern, Switzerland.

(Received February 7, 1994; revised April 8, 1994; accepted April 8, 1994.)

\footnotetext{
${ }^{1}$ Now at Physics Institute, University of Bern, Bern, Switzerland.

Copyright 1994 by the American Geophysical Union.

Paper number 94JC00956.

0148-0227/94/94JC-00956\$02.00
} 